At operation (H. B.E.) on 18 February 1965 a preliminary cystoscopy showed a normal bladder. Retrograde catheterization of the left ureter showed no ureteric obstruction. The left kidney was exposed through a loin incision.

On exposing the kidney and opening the renal pelvis there was pus present in the upper calices, but there was no pelvi-ureteric obstruction. The stone was removed through the renal pelvis and the pelvis was irrigated with saline. Because of the child's gross

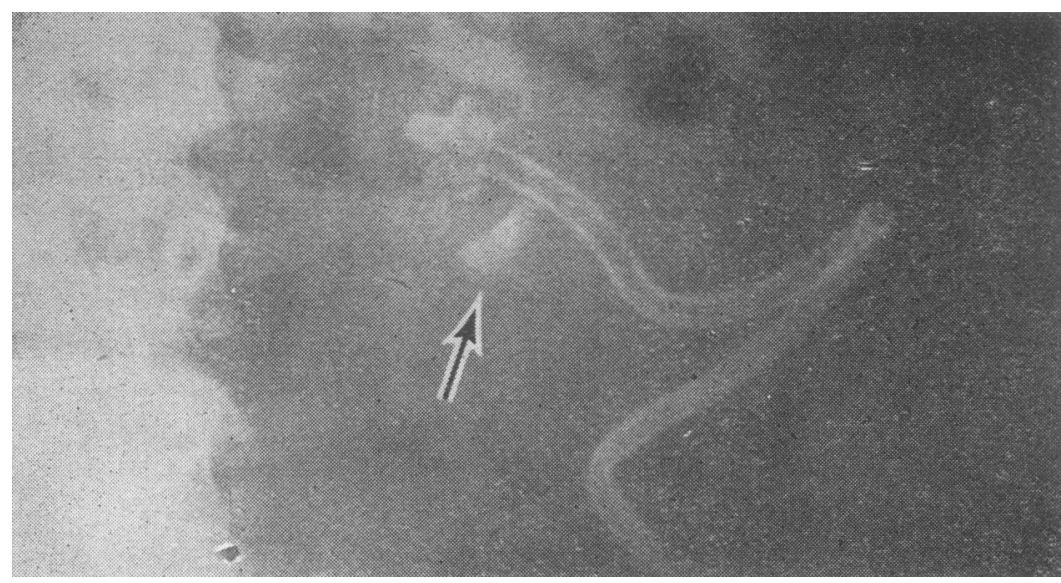

FIG. 2.-Post-operative radiograph showing fragment of calculus (arrowed) in minor calyx at lower pole of kidney.

obesity exposure of the kidney was very difficult, and radiography of the exposed kidney proved to be impossible.

A post-operative radiograph of the abdomen showed the presence of a fragment of the calculus in a minor calyx at the lower pole of the kidney (Fig. 2). In view of this finding it was decided to irrigate the kidney through the nephrostomy tube with a $10 \%$ solution of Renacidin at the rate of 1 pint (0.6 litre) per day from 5 March 1965. The patient had no untoward symptoms during this procedure.

A radiograph of the abdomen three days later showed the calculus to be much smaller. It was also noted that the urine collected in between the irrigation contained gritty particles.

On 22 March 1965 a further radiograph of the abdomen revealed no calculus. A left retrograde pyetogram was therefore carried out on 1 April 1965, and showed that there was no evidence of a nonopaque stone.

\section{Retinal Detachment with Spontaneous Regression in Renal Failure}

\section{Brit. med. F., 1966, 2, 92-93}

The occurrence of reversible retinal detachment in renal failure is not well known. Lapco, Weller, and Greene (1965) have drawn attention to this association, and we report here a further example.

\section{CASE Report}

A 21-year-old white woman was admitted to hospital with renal failure, probably due to chronic glomerulonephritis. She had had no relevant past illnesses, but proteinuria had been detected on routine examination two years previously. She gave a five-weeks history of malaise, nausea, vomiting, and swelling of the ankles. Two weeks before admission she experienced diffuse abdominal pain, and in the last 10 days her vision had become increasingly blurred. Physical examination revealed periorbital and facial puffiness, sacral
When the stone was analysed it was found to be composed of calcium phosphate, small amounts of magnesium ammonium phosphate, and traces of sodium and potassium. There was no trace of urates.

\section{COMMENT}

Though there are a number of reports on the use of Renacidin as the sole method of treatment of large renal calculi, especially in cases that are a poor surgical risk, we think that it cannot replace surgery in patients fit for operation. Surgery, in addition to having a low incidence of post-operative complications, provides an opportunity for any plastic operation to be carried out on the renal pelvis at the same time. Renacidin is, however, invaluable for postoperative irrigation to eliminate grit and residual calculi, as in our case, and is more efficient than Suby's solution for this purpose. We did not notice any reaction following the use of Renacidin in this patient after its daily use for 17 days.

Another feature noted was that the catheter used for the nephrostomy did not show any evidence of alkaline encrustation around it in spite of it being in the renal pelvis for 17 days. Renacidin has been recommended for irrigation of urethral catheters to prevent encrustation when these catheters have to be retained for long periods without repeated changing.

Pain and febrile reactions have been reported when a ureteric catheter has been used for irrigation (Kohler, 1962). However, as Fostvedt and Barnes (1963) have reported four deaths following Renacidin therapy-in one of these fatalities a nephrostomy tube had been used-treatment with Renacidin cannot be considered to be without risk.

\section{K. SOMASUNDARAM, F.R.C.S., Surgical Registrar. \\ H. B. ECKSTEIN, M.D., M.CH., F.R.C.S., Consultant Surgeon. \\ Queen Mary's Hospital for Children, Carshalton.}

\section{REFERENCES}

Fostvedt, G. A., and Barnes, R. W. (1963). F. Urol. (Baltimore), 89, 329. Kohler, F. P. (1962). Ibid., 87, 102.

Mulvaney, W. P. (1960). Ibid., 84, 206. oedema, anaemia, acidotic breathing, blood-pressure $200 / 125$, triple rhythm, and generalized abdominal tenderness. The optic fundi showed venous dilatation and slight blurring of the right disc margin.

The serum sodium concentration was $121 \mathrm{mEq} / 1$, potassium 5.2 $\mathrm{mEq} / 1$., plasma bicarbonate $18 \mathrm{mEq} / 1$., blood urea $335 \mathrm{mEq} / \mathrm{l}$., and haemoglobin $8.5 \mathrm{~g} . / 100 \mathrm{ml}$. The serum cholesterol was $240 \mathrm{mg} . /$ $100 \mathrm{ml}$. and the total serum protein $6.5 \mathrm{~g} . / 100 \mathrm{ml}$., with normal albumin, increase in alpha-1 and alpha- 2 globulins, and decrease in gamma-globulin. The urine contained protein, red and white blood cells, and hyaline casts. A throat swab was sterile, and the antistreptolysin-O titre was less than 50 Todd units/ml. Retrograde pyelography showed normal pelvi-caliceal systems and ureters, but the renal outlines were not well defined. Attempted renal biopsy was unsuccessful.

The patient was oliguric (urine output less than $600 \mathrm{ml} . / 24$ hours), and remained so throughout her stay in hospital. Four days after admission twin-coil haemodialysis was carried out. During dialysis $2,500 \mathrm{ml}$. of body water was removed by ultrafiltration, the electrolyte abnormalities were corrected, and blood transfusion was given. She was maintained on a strict oliguric-renal-failure regimen, and three further haemodialyses were performed at weekly intervals; 
oedema, which disappeared after the first dialysis, did not recur. Methyldopa was given for her hypertension, but her blood-pressure was poorly controlled, ranging between 180/110 and 160/100. Facilities for long-term dialysis were not available, and after five weeks in hospital she was discharged home, where she died 10 days later.

During the first few days after admission her visual acuity rapidly deteriorated until she was only able to perceive light with the right eye and count fingers with the left eye. Ophthalmoscopic examination on the sixth day after admission showed almost complete detachment of the retina of the right eye and a partial retinal detachment in the left. The detachments were most pronounced inferiorly, and in the right eye the entire lower half of the retina protruded forward as an almost horizontal shelf. Thereafter her vision progressively improved and the retinal changes regressed. At the time of discharge she was able to read newsprint with each eye, and only small areas of detachment at the lower poles of each retina remained.

\section{COMMENT}

Lapco et al. (1965) described eight cases of retinal detachment and chronic renal failure, but previously the association has only rarely been reported (Wagener, 1927 ; Mettier, 1961 ; Buchanan and Ellis, 1964). Duke-Elder (1940) referred to exudative detachment as a rare complication of renal failure and mentioned that the condition might resolve if the patient survived long enough. In each of the eight patients of Lapco et al. (1965) the retina reattached, at intervals of 1 to 16 weeks ; and in our patient the condition had almost completely remitted within five weeks.

The pathogenesis of the detachment is not clear, but its predominantly dependent location suggests that it results from the accumulation of fluid behind the retina. Lapco et al. (1965) found no correlation between the degree of the detachment and the severity of either hypertension or azotaemia; but they related regression of the lesion to loss of body water. In our patient, improvement occurred at a time when her oedema and dilutional hyponatraemia had been controlled by haemodialysis and fluid restriction, and was maintained, though she remained hypertensive and the blood urea rose to over $300 \mathrm{mg} . / 100 \mathrm{ml}$. between haemodialyses. The occurrence of spontaneous retinal detachment in toxaemia of pregnancy (Bosco, 1961) adds support to the idea of increased body water as a causative factor. Lapco et al. (1965) suggested that hypoalbuminaemia might be a contributory cause, but in our patient the serum albumin concentration was normal.

Reversible retinal detachment seems to be a rare complication of renal failure, but an increased awareness of the condition is likely to lead to its more frequent recognition.

We are grateful to Professor J. Anderson for permission to publish this case report, and to Mr. L. H. Savin for the ophthalmological findings.

\section{Registrar to the Medical Unit, King's College Hospital, London. \\ H. A. LEE, M.B., B.SC., M.R.C.P.,}

P. SHARPSTONE, M.B., M.R.C.P.,

Lecturer in Medicine, University Department of Medicine, Royal Infirmary, Manchester.

\section{REFERENCES}

Buchanan, W. S., and Ellis, P. P. (1964). Arch. Ophthal., 71, 182.

Bosco, J. A. (1961). Amer. F. Obstet. Gynec., 82, 208.

Duke-Elder, W. S. (1940). Text-Book of Ophthalmology, vol. 3, p. 2717. Kimpton, London.

Lapco, L., Weller, J. M., and Greene, J. A. (1965). Ann. intern. Med., 63, 760 .

Mettier, S. R. (1961). Arch. Ophshal., 65, 386.

Wagener, H. P. (1927). Trans. Amer. ophthal. Soc., 25, 349.

\section{Lower Limb Palsies with Hypo- prothrombinaemia}

Brit. med. F., 1966, 2, 93-94

Peripheral nerve lesions complicating intramuscular haemorrhage are not uncommon in bleeding disorders such as haemophilia. They are also said to occur in patients on anticoagulants (Douglas, 1962), and it was thought worth while reporting three such cases in detail.

\section{CASE 1}

A 62-year-old businessman was admitted to St. Mary's Hospital on 10 January 1964. In 1959 he suffered a myocardial infarct, and treatment with anticoagulants was started. Three months later he developed intermittent claudication in the left leg, and aortography demonstrated diffuse arterial disease. His prothrombin time remained well controlled on phenindione, $75 \mathrm{mg}$. twice daily, until December 1963, when he developed a productive cough, and a course of tetracycline was prescribed. By 26 December he had some haemoptysis, and on 6 January 1964 he noticed increasing pain and weakness in his right thigh over a period of two hours. After this he passed a melaena stool and vomited black material. He was admitted to hospital in a stuporous condition and very pale, and responded only to painful stimuli. There was superficial abdominal bruising, and two masses, one just below the left costal margin and the other in the right iliac fossa, which were thought to be haematomata within muscles, were palpated.

The pulse rate was $84 / \mathrm{min}$. and regular. The blood-pressure was $130 / 80 \mathrm{~mm}$. Hg. There were no pulses palpable below the femorals. As his haemoglobin level was $31 \%$ (4.5 g. $/ 100 \mathrm{ml}$.) and the prothrombin time over 60 seconds, he was transfused with 5 pints (2.8 litres) of blood and given vitamin $K_{1}, 20 \mathrm{mg}$. intravenously. Later that evening he recovered sufficiently to give a history, and neurological signs were then elicited. The cranial nerves and upper limbs showed no abnormality. There was severe weakness of hip flexion and knee extension on the right, an absent right knee jerk, and superficial sensory loss over the front of the thigh and knee on this side. The left leg was normal, as was distal power in the right, and both plantar responses were flexor. 'The only other neurological abnormality was impaired vibration sensation in both legs below the iliac crests.

Investigations failed to demonstrate any source for the gastrointestinal haemorrhage.

The prothrembin time returned to normal rapidly, but motor power and sensation were slow in returning to the right leg. By the time of his discharge a month later he was able to walk with the assistance of a knee calliper. Motor power in the right quadriceps remained poor and the right knee jerk was still absent.

\section{CASE 2}

A 53-year-old company director was admitted to St. Marry's Hospital on 9 July 1964 . In 1961 he had had a myocardial infarct, and treatment with phenindione was started.

In July 1964 he was on honeymoon on the Continent, taking his phenindione rather erratically, and noticed that he was bruising very readily. Bleeding from minor scratches was difficult to stop. On 8 July he woke at 5 a.m. with severe pain in the front of both thighs. The pain was constant, radiated from the groins to the knees, and was aggravated by movement. He was flown back to London the next day. Examination revealed a man in pain, with superficial bruising of the left hand and upper arm, the abdomen, and left thigh. His cranial nerves and upper limbs were normal. 